\title{
A EVASÃO NA UNIVERSIDADE FEDERAL DE MATO GROSSO DO SUL (2008- 2012)
}

The dropout at the Universidade Federal de Mato Grosso do Sul (2008-2012)

La evasión en la Universidad Federal de Mato Grosso do Sul (2008-2012)

\author{
Mauro Cunha Júnior \\ Silvia Helena Andrade de Brito ${ }^{* *}$ \\ Carina Elisabeth Maciel $^{* * * *}$
}

\begin{abstract}
Resumo
Este artigo, inserido no campo de estudos da educação superior, tem como objeto de investigação a evasão na Universidade Federal de Mato Grosso do Sul (UFMS). O objetivo geral é analisar o processo de evasão na UFMS no período em que foi implementado o Programa de Apoio a Planos de Reestruturação e Expansão das Universidades Federais (Reuni), considerando estudantes ingressantes em cursos de graduação nos anos de 2008 a 2012; e que concluíram sua graduação entre os anos de 2013 a 2018, no campus de Campo Grande. Para atingir o objetivo proposto, recorreu-se, por um lado, à coleta de documentos institucionais e compilação de dados oficiais. Por outro, foi levantada a produção já existente sobre a temática. Como resultado, os dados demonstraram que a evasão foi elevada no período considerado, em 43,5\%. E, mais precisamente, o ano de 2011 apresentou o percentual mais significativo (56,3\%). Além disso, constatou-se que cursos da Grande Área "Ciências Exatas e da Terra" apresentaram médias mais expressivas de evasão $(63,3 \%)$, assim como os cursos voltados para a formação de tecnólogos $(74,8 \%)$ e as carreiras ofertadas no período noturno $(60,5 \%)$.
\end{abstract}

PALAVRAS-CHAVE: Evasão. Educação superior. Universidade Federal de Mato Grosso do Sul.

\begin{abstract}
This article, inserted in the field of studies of higher education, has as object of investigation the dropout at the Federal University of Mato Grosso do Sul (UFMS). The general objective is to analyze the dropout process at UFMS during the period in which the Program to Support Restructuring and Expansion Plans of Federal Universities (Reuni), considering students entering undergraduate courses in the years 2008 to 2012; and who completed their graduation between the years 2013 the 2018, on the campus of Campo Grande. To achieve the proposed objective, the collection of institutional documents and compilation of official data was used. On the other hand,

\footnotetext{
*Bacharel em Ciências Sociais. Mestrando do Programa de Pós-Graduação em Educação pela Faculdade de Educação da Universidade Federal de Mato Grosso do Sul. E-mail: mauro.junior6@hotmail.com. Orcid: https://orcid.org/0000-0002-6906-7786

** Doutora em Educação. Docente do Programa de Pós-Graduação em Educação pela Faculdade de Educação da Universidade Federal de Mato Grosso do Sul. E-mail: silvia.brito@ufms.br. Orcid: https://orcid.org/00000002-6186-3980

**** Doutora em Educação pela Faculdade de Educação da Universidade Federal de Mato Grosso do Sul. Docente da Faculdade de Educação e do Programa de Pós-Graduação em Educação pela Faculdade de Educação da Universidade Federal de Mato Grosso do Sul. E-mail: carina22em@gmail.com. Orcid: https://orcid.org/0000-0003-3765-3139
} 
the production already produced on the theme was raised. As a result, the data showed that dropout was high, in the period considered, in 43,5\%. And more precisely, 2011 presented the most significant percentage (56,3\%). In addition, it was found that courses in the Large Area "Exact and Earth Sciences" presented more expressive means of dropout $(63,3 \%)$, as well as the courses focused on the formation of technologists $(74,8 \%)$ and the careers offered during the night $(60,5 \%)$.

KEYWORDS: Dropout. Higher education. Federal University of Mato Grosso do Sul.

\section{Resumen}

Este artículo, insertado en el campo de los estudios de educación superior, tiene como objeto de investigación la deserción en la Universidad Federal de Mato Grosso do Sul (UFMS). El objetivo general es analizar el proceso de deserción en UFMS durante el período en que se implementó el Programa de Apoyo a los Planes de Reestructuración y Expansión de las Universidades Federales (Reuni), considerando a los estudiantes que ingresan a cursos de graduación en los años 2008 a 2012; y que completaron su graduación entre los años 2013 el 2018, en el campus de Campo Grande. Para lograr el objetivo propuesto se utilizó la recopilación de documentos institucionales y de datos oficiales. Por otro lado, se buscó la producción ya existente sobre el tema. Como resultado, los datos mostraron que la deserción fue alta durante el período considerado, en 43,5\%. Y, más precisamente, 2011 tuvo el porcentaje más significativo (56,3\%). Además, se descubrió que los cursos en el área "Ciencias Exactas y de la Tierra" tenían mayores tasas de deserción (63,3\%), así como cursos tecnológicos $(74,8 \%)$ y los cursos ofrecidos por la noche $(60,5 \%)$.

PALABRAS CLAVE: Evasión. Educación universitaria. Universidad Federal de Mato Grosso do Sul.

\section{INTRODUÇÃO}

Este artigo tem como objeto de investigação a evasão ${ }^{1}$ na Universidade Federal de Mato Grosso do Sul (UFMS). O objetivo geral é analisar o processo de evasão na UFMS no período em que foi implementado o Programa de Apoio a Planos de Reestruturação e Expansão das Universidades Federais (Reuni), coordenado pelo Ministério da Educação (MEC), considerando estudantes ingressantes em cursos de graduação via vestibular e por meio do Sistema de Seleção Unificada $(\mathrm{Sisu})^{2}$ nos anos de 2008 a 2012, e que concluíram sua graduação entre os anos de 2013 a 2018, no campus de Campo Grande.

Para atingir o objetivo proposto, recorreu-se à coleta de documentos institucionais e compilação de dados oficiais por meio do Instituto Nacional de Estudos e Pesquisas Educacionais "Anísio Teixeira" (Inep) - os microdados do Censo da Educação Superior (2009-2018) $)^{3}$, por um lado. Por outro, foi levantada e analisada a literatura referente a

\footnotetext{
${ }^{1}$ Neste artigo, compreendemos evasão a partir do conceito apresentado pela Comissão Especial de Estudos sobre a Evasão nas Universidades Públicas Brasileiras (1997). Dessa forma, entendemos como evasão a saída do estudante de seu curso de origem, sem concluí-lo.

${ }^{2}$ Como relatam Luz e Veloso (2014), "O SiSU, assim como o Novo Enem, foram apresentados à sociedade em 31 de março de 2009, em Brasília, pelo ex-Ministro de Educação, Fernando Haddad. É um sistema informatizado coordenado pelo MEC, o qual utiliza a nota obtida pelo estudante no ENEM para ingressá-lo em determinada instituição que praticou o processo de adesão ao sistema". No ano de 2010, o Sisu foi regulamentado pela Portaria Normativa MEC $\mathrm{n}^{\mathrm{o}} 2$, de 26 de janeiro de 2010, e posteriormente passou a ser regido pela Portaria Normativa $n^{\circ} 21$, de 05 de novembro de 2012 (BRASIL, 2012). Cabe salientar que a atual configuração do Sisu - 2020 - inclui as seguintes etapas: inscrição, primeira chamada e lista de espera.

${ }^{3}$ Os microdados do Inep se constituem no menor nível de desagregação de dados recolhidos por pesquisas, avaliações e exames realizados. Os dados do Censo da Educação Superior fornecidos pelo Inep passaram a ser individualizados a partir de 2009. Desta forma, a título de esclarecimento, ressaltamos que, mesmo não
} 
temática (ADACHI, 2009; 2017; BARBOSA et al., 2017; DAVOK; BERNARD, 2016; LI, 2016; VELOSO; ALMEIDA, 2002). Cabe destacar que o método de investigação pode ser caracterizado segundo a Comissão Especial de Estudos sobre a Evasão nas Universidades Públicas Brasileiras (1997) ${ }^{4}$ como de fluxo ou de acompanhamento de estudantes, configurando-se como um estudo longitudinal. Assim, busca-se analisar o processo de evasão em cursos de graduação para estudantes de geração completa ${ }^{5}$.

O artigo está organizado em duas seções, além da introdução e das considerações finais. A primeira seção tem como objetivo apresentar a UFMS, considerando seu processo de criação na segunda metade do século XX e expansão a partir dos anos 2000 . Na segunda seção, propõe-se analisar o processo de evasão na referida instituição. Para isso, são apresentados dados que dizem respeito ao número de estudantes ingressantes e evadidos nos anos de 2008 a 2012; a evasão média segundo as grandes áreas do conhecimento; a evasão média por grau acadêmico conferido e, por último, a evasão média por período de oferecimento do curso.

\section{A criação da Universidade Federal de Mato Grosso do Sul}

A origem da educação superior pública na região Sul de Mato Grosso remonta à criação da Faculdade de Farmácia e Odontologia em 1962, na cidade de Campo Grande. Alguns anos depois, em 1969, por meio da Lei Estadual $n^{\circ} 2.947$, de 16 de setembro, foi criada a Universidade Estadual de Mato Grosso (UEMT), com sede em Campo Grande, integrando os Institutos de Campo Grande, Corumbá e Três Lagoas ${ }^{6}$. A estes últimos, nos anos 1970, foram acrescidos os Centros Pedagógicos de Aquidauana, Dourados e o Centro Pedagógico de Rondonópolis, sediado em Rondonópolis/MT ${ }^{7}$.

Com a divisão do Estado de Mato Grosso ${ }^{8}$ foi concretizada a federalização da instituição, que passou a denominar-se Fundação Universidade Federal de Mato Grosso do

\footnotetext{
tendo acesso aos dados particularizados de estudantes ingressantes em 2008, foi possível calcular a evasão nesse primeiro ano subtraindo-se o número de ingressantes de 2008, pelo número de estudantes que estavam vinculados em 2009.

${ }^{4}$ A Comissão Especial de Estudos sobre a Evasão nas Universidades Públicas Brasileiras (1997), doravante denominada Comissão Especial, se propôs a determinar os índices de retenção, diplomação e evasão de cursos de graduação, para turmas de geração completa que ingressaram na segunda metade da década de 1980 e formaram-se na primeira metade da década de 1990, nas IES públicas brasileiras. A Comissão constitui-se em trabalho pioneiro e inovador para o sistema de educação superior por sua abrangência nacional e pela adoção de um modelo metodológico capaz de dar uniformidade aos processos de coleta e tratamento de dados (ADACHI, 2017).

5 Segundo a Comissão Especial (1997), por geração completa entende-se a situação do conjunto de ingressantes em um determinado curso, em um ano/semestre, ao final do prazo máximo de integralização curricular. Para a UFMS (2016), o tempo máximo, em semestres, para a integralização curricular, é calculado adicionando-se cinquenta por cento do tempo proposto como necessário para a integralização curricular do curso de graduação.

${ }^{6}$ Destaque-se que no ano seguinte, em 10 de dezembro de 1970, foi criada a Universidade Federal de Mato Grosso, com sede em Cuiabá.

7 Com a divisão do Estado, em 1977, deu-se início ao processo de federalização do atual Campus Universitário de Rondonópolis, integrando-o à Universidade Federal de Mato Grosso (UFMT), uma vez que o município de Rondonópolis passava a pertencer ao Estado de Mato Grosso, agora dividido em duas unidades federativas.

${ }^{8}$ A decisão de desmembrar Mato Grosso e criar Mato Grosso do Sul foi tomada em abril de 1977 pelo terceiro presidente do regime militar, Ernesto Geisel, seis meses antes da assinatura da Lei Complementar $\mathrm{n}^{\circ}$ 31 , em 11 de outubro.
} 
Sul (UFMS) pela Lei Federal $\mathrm{n}^{\circ}$ 6.674, de 5 de julho de 1979, com sede em Campo Grande, capital do Estado de Mato Grosso do Sul (MS).

Em 2001, a UFMS implantou os campi de Coxim (CPCX) e de Paranaíba (CPAR). Entre 2004 e 2005, foram criadas novas unidades setoriais nas cidades de Chapadão do Sul (CPCS), Naviraí (CPNV), Nova Andradina (CPNA) e Ponta Porã (CPPP) ${ }^{9}$. Ainda em 2005, foram criadas a Faculdade de Medicina (FAMED), a Faculdade de Medicina Veterinária e Zootecnia (FAMEZ) e a Faculdade de Odontologia (FAODO) na cidade de Campo Grande (UFMS, 2017).

Com vistas ao processo de expansão das Ifes, em 2007, pelo Decreto n ${ }^{\circ}$ 6.096, de 24 de abril, o governo federal instituiu o Reuni, com objetivo de criar condições para a ampliação do acesso e permanência na educação superior, no nível de graduação, pelo melhor aproveitamento da estrutura física e de recursos humanos existentes nas universidades federais. Sua meta global era a elevação gradual da taxa de conclusão média dos cursos de graduação presenciais para noventa por cento e da relação de alunos de graduação em cursos presenciais por professor para dezoito, ao final de cinco anos, a contar do início de cada plano (BRASIL, 2007).

Além disso, cabe salientar que o programa Reuni tinha como diretrizes: 1. redução das taxas de evasão, ocupação de vagas ociosas e aumento de vagas de ingresso, especialmente no período noturno; 2. ampliação da mobilidade estudantil, com a implantação de regimes curriculares e sistemas de títulos que possibilitem a construção de itinerários formativos, mediante o aproveitamento de créditos e a circulação de estudantes entre instituições, cursos e programas de educação superior; 3. revisão da estrutura acadêmica, com reorganização dos cursos de graduação e atualização de metodologias de ensino-aprendizagem, buscando a constante elevação da qualidade; 4. diversificação das modalidades de graduação, preferencialmente não voltadas à profissionalização precoce e especializada; 5. ampliação de políticas de inclusão e assistência estudantil e 6. articulação da graduação com a pós-graduação e da educação superior com a educação básica (BRASIL, 2007).

A UFMS aderiu ao Reuni em 2007, comprometida com a abertura de 1.726 vagas nos cursos de graduação, ensino presencial, o que incluía o aumento de vagas nos cursos existentes e a criação de 28 cursos no período de 2008 a 2012, distribuídos pelos Centros e Faculdades em Campo Grande, bem como no interior de Mato Grosso do Sul (Campi de Aquidauana, Coxim, Chapadão do Sul, Nova Andradina, Paranaíba, Pantanal, Três Lagoas), além da criação de três novos Campi localizados nas cidades de Bonito, Naviraí e Ponta Porã.

As justificativas apresentadas para adesão ao Reuni foram em razão da possibilidade de contribuir com a inserção do governo federal na educação superior em Mato Grosso do Sul, ampliando as oportunidades para os jovens da faixa etária de 18 a 24 anos; ampliação da interiorização em Mato Grosso do Sul, incluindo mais três cidades com Unidades Setoriais, ocupando localizações estratégicas no cenário macroeconômico do Estado. Outro motivo apresentado foi a distribuição de cursos pelo Estado voltados para a formação de professores, pretendendo contribuir assim para o crescimento do número de jovens que seriam os futuros professores e profissionais da educação (UFMS, 2010).

\footnotetext{
${ }^{9}$ Ademais, importa mencionar que, ao mesmo tempo que ocorria o referido movimento de expansão da UFMS, o Campus de Dourados (CPDO) foi desmembrado da UFMS e transformado na Fundação Universidade Federal da Grande Dourados (UFGD), em 2005, tendo ocorrido a sua implantação em $1^{\circ}$ de janeiro de 2006.
} 
Nessa direção, seguindo as diretrizes do programa Reuni, foram implantados os cursos de graduação nos campi de Bonito (CPBO) ${ }^{10}$, Naviraí (CPNV) e Ponta Porã (CPPP), a partir do ano letivo de 2009; e, em Campo Grande, foram implantadas a Faculdade de Computação (FACOM) e a Faculdade de Direito (FADIR) (UFMS, 2010).

Além dos novos campi e faculdades, decorrentes do processo de expansão previsto no Reuni, foi necessária a reestruturação da administração universitária - perspectiva já presente nas diretrizes mais gerais do programa - com o surgimento de novas unidades administrativas, muitas delas inclusive abrigando os cursos criados pelo Reuni ${ }^{11}$. Dessa forma: a) em 2013, foram criados o Instituto de Física (INFI), o Instituto de Química (INQUI) e o Instituto de Matemática (INMA), bem como a Faculdade de Engenharias, Arquitetura e Urbanismo e Geografia (FAENG), em razão do desmembramento e respectiva desativação do Centro de Ciências Exatas e Tecnologia (CCET); b) em 2014 foi criada a Escola de Administração e Negócios; c) já no ano de 2017 foram criados o Instituto de Biociências (INBIO) e o Instituto Integrado de Saúde (INISA), bem como a Faculdade de Ciências Farmacêuticas, Alimentos e Nutrição (FACFAN); a Faculdade de Ciências Humanas (FACH); a Faculdade de Educação (FAED) e a Faculdade de Artes, Letras e Comunicação (FAALC), com o desmembramento e extensão do Centro do Ciências Biológicas e Saúde (CCBS) e o do Centro de Ciências Humanas e Sociais (CCHS) (UFMS, 2017).

Nesse contexto, pode-se verificar que:

[...] a UFMS vivenciou uma fase de grandes investimentos que tornaram possível a expansão das atividades de ensino, pesquisa e extensão. Novos cursos de graduação e pós-graduação foram criados, aumentando as oportunidades para qualificação de jovens e de profissionais, os programas de auxílio aos estudantes foram ampliados, permitindo que a permanência dos mesmos na Universidade se solidificasse. Para atender a esse crescimento, foram feitos investimentos em recursos humanos por meio da realização de concursos e promoção de programas de qualificação de docentes e técnicos [...] A infraestrutura também foi ampliada com a construção de novos prédios e reformas nos existentes. Para que isso fosse possível, o apoio do Governo Federal se fez presente, com os recursos vindos do Programa de Reestruturação e Expansão das Universidades Federais (Reuni). (UFMS, [2015?], p. 6-7).

Em vista do processo de expansão vivenciado pela UFMS - em particular até $2015^{12}$-, com especial atenção para o período que cobre a implementação do Reuni, entre 2008 a 2012, na próxima seção deste artigo analisaremos a evasão nesta instituição, no campus de Campo Grande. Desta forma, são apresentados dados que dizem respeito ao número de estudantes ingressantes nos anos de 2008 a 2012, e evadidos entre 2008 e 2018; a evasão média segundo as oito Grandes Área do Conhecimento (Ciências Exatas e da

\footnotetext{
${ }^{10}$ Embora tenha ocorrido a implantação do Campus de Bonito, o mesmo foi fechado em 2015 sob alegação de insuficiência de alunos.

${ }^{11}$ A título de exemplo, cita-se o Curso de Bacharelado em Geografia, criado em 2011, agregado à Faculdade de Engenharias, Arquitetura e Urbanismo e Geografia (FAENG); e o Curso de Licenciatura em Filosofia, criado em 2009, lotado na Faculdade de Ciências Humanas (FACH).

${ }^{12}$ De acordo com o jornal eletrônico O Estado de S. Paulo (Estadão), em 31 de agosto de 2017, o orçamento das Universidades Federais do País caiu R\$ 3,4 bilhões em três anos (2014 a 2017), saindo de R\$ 10,72 bilhões em 2014 para R \$ 7,34 bilhões em 2017. Houve ainda diminuição de mais da metade dos recursos de investimento (de $\mathrm{R} \$ 3,7$ bilhões para $\mathrm{R} \$ 1,4$ bilhão) e de $16 \%$ no custeio (de $\mathrm{R} \$$ 7,02 bilhões para $\mathrm{R} \$ 5,89$ bilhões). Cf. https://educacao.estadao.com.br/noticias/geral,orcamento-das-universidades-federais-do-paiscai-r-3-4-bilhoes-em-tres-anos,70001957732. Acesso em: 20 nov. 2019.
} 
Terra, Ciências Biológicas, Engenharias, Ciências da Saúde, Ciências Agrárias, Ciências Sociais Aplicadas, Ciências Humanas e Linguística, Letras e Artes); a evasão média por grau acadêmico (Bacharelado, Licenciatura e Tecnológico) e, por último, a evasão média por período (Integral e Noturno).

\section{Evasão em cursos de graduação da Universidade Federal de Mato Grosso do Sul}

Inicialmente, para o desenvolvimento desta segunda seção, foram acessados, no sítio do Inep, os microdados do Censo da Educação Superior (2009-2018) ${ }^{13}$, como já mencionado na introdução deste artigo. Dessa maneira, analisamos os dados concernentes à variável relacionada ao aluno, nesse caso, a variável situação de vínculo do aluno no curso (cursando; matrícula trancada; desvinculado do curso; transferido para outro curso da mesma IES; formado ou falecido), o que nos permitiu identificar, na trajetória formativa de estudantes da UFMS, condições de evasão, permanência prolongada e conclusão em cursos de graduação. No caso deste artigo, evidenciaremos apenas a condição referente à evasão.

Fundamentalmente, foram 34 (trinta e quatro) os cursos de graduação pesquisados. Para a seleção desses cursos, consideramos dois aspectos: 1) cursos criados no período de implementação do Reuni na UFMS: Licenciatura em Ciências Biológicas; Fisioterapia; Nutrição; Tecnologia em Alimentos; Engenharia de Produção; Geografia; Tecnologia em Construção de Edifícios; Tecnologia em Saneamento Ambiental; Tecnologia em Eletrotécnica Industrial; Filosofia; Tecnologia em Processos Gerenciais; Tecnologia em Análise e Desenvolvimento de Sistemas; Tecnologia em Redes de Computadores e Engenharia da Computação. E, 2) cursos que foram ampliados nesse período: Bacharelado em Ciências Biológicas; Farmácia; Arquitetura e Urbanismo; Engenharia Ambiental; Engenharia Civil; Engenharia Elétrica; Licenciatura em Física; Administração - Noturno; Administração - Integral; Ciências Econômicas; História; Comunicação Social; Letras Português/Espanhol e Letras - Português/Inglês; Pedagogia; Psicologia; Odontologia; Medicina Veterinária; Análise de Sistemas e Ciência da Computação. Buscou-se realizar a análise do processo de evasão para até cinco séries históricas (2008-2015; 2009-2016; 2010-2017; 2011-2018 e 2012-2018 ${ }^{14}$ ), considerando a metodologia estabelecida pela Comissão Especial, já citada anteriormente.

Em vista da análise de tal processo, o gráfico 1 salienta o número de alunos ingressantes e evadidos na UFMS, considerando como data de início do curso o período 2008-2012.

Dessa forma, alguns apontamentos devem ser realizados. A princípio, nota-se que do total de 6.437 estudantes ingressantes nesse período, 2.799 abandonaram seus cursos, o que representou um percentual elevado de evasão, totalizando 43,5\%. Além do mais, conforme a distribuição dos anos no gráfico, nota-se que o número mais significativo de alunos que interromperam seu processo de formação foi evidenciado no conjunto de

\footnotetext{
${ }^{13}$ Para extração dos dados foi utilizado o Statistical Package for the Social Sciences (SPSS), versão 22, ano 2013.

${ }^{14}$ Tendo em vista que estamos analisando estudantes de geração completa, considerando o tempo máximo para integralização curricular, não foram analisados, para o ano de 2012, os cursos que possuem tempo máximo de integralização de 15 semestres (Engenharia de Produção; Engenharia da Computação; Farmácia; Arquitetura e Urbanismo; Engenharia Ambiental; Engenharia Civil; Engenharia Elétrica; Psicologia e Medicina Veterinária), isto porque até o momento da escrita do artigo os microdados do Censo de 2019 não haviam sido divulgados.
} 
ingressantes do ano de $2011^{15}$. Assim, dos 1.686 alunos que ingressaram nesse ano, 950 (56,3\%) não chegaram a concluir o curso. Em compensação, nota-se que os anos de 2008 e 2009 apresentaram números menos expressivos de abandono, com 288 (32,9\%) e 272 $(30,7 \%)$ estudantes evadidos entre os ingressantes nesses dois anos, respectivamente. Dessa maneira, considerando-se a análise panorâmica da evasão na UFMS, e com base na literatura já produzida sobre a temática ${ }^{16}$ (LI, 2016; BARBOSA et al., 2017), levantamos como hipótese a assertiva de que o crescimento do número de estudantes evadidos pode estar associado a mudança do processo de seleção de alunos, por meio da adoção do Sisu pela UFMS, a partir do segundo semestre de 2010.

Gráfico 1. Quantitativo de estudantes ingressantes e evadidos na UFMS - 2008 a 2012

Ingressantes x Evadidos

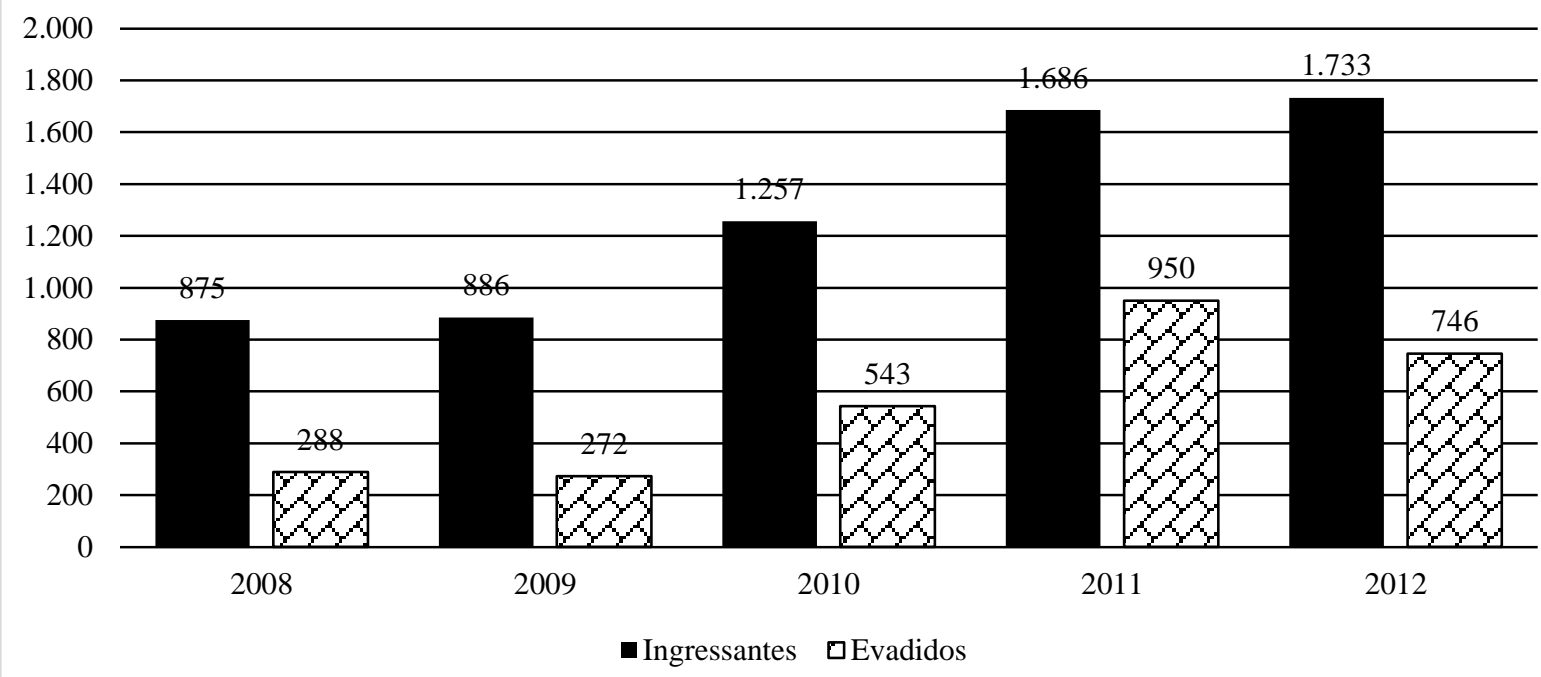

Fonte: Elaborado a partir dos microdados do Censo da Educação Superior (2009-2018).

Frente a isto, nesse momento, partimos para análise de algumas particularidades da evasão na Ifes em questão. Desse modo, no gráfico 2, é relatada a média de evasão pelas oito Grandes Áreas do Conhecimento, quais sejam: Ciências Exatas e da Terra ${ }^{17}$; Ciências Biológicas ${ }^{18}$; Engenhariass ${ }^{19}$; Ciências da Saúde ${ }^{20}$; Ciências Agráriass ${ }^{21}$; Ciências Sociais Aplicadas $^{22}$; Ciências Humanas ${ }^{23}$ e Linguística, Letras e Artes ${ }^{24}$.

\footnotetext{
${ }^{15}$ Na UFMS - Cidade Universitária (Campo Grande) e campi do interior do Estado -, as desistências foram responsáveis por 81,79\% das exclusões ocorridas em 2011, seguida pelas solicitações de alunos que representaram 16\%. Já as transferências, representaram apenas 2,21\% do total das exclusões (UFMS, 2012).

${ }^{16} \mathrm{Na}$ pesquisa realizada por $\mathrm{Li}$ (2016), constatou-se que o aluno que ingressa em um programa que oferta vagas pelo Sisu tem uma probabilidade maior de mudar de instituição antes de completar o curso. Já no estudo realizado por Barbosa et al. (2017), que teve como principal objetivo verificar a evolução do percentual de alunos evadidos nos anos antes e depois da adoção do Sistema de Seleção Unificada (Sisu) na Universidade Federal de Uberlândia (UFU), os resultados permitiram inferir que a adoção do Sisu pode ter afetado a evasão na UFU, mas os impactos são diversos, conforme as áreas de conhecimento, ou, talvez, conforme o curso.

${ }^{17}$ Cursos de Licenciatura em Física; Análise de Sistemas; Tecnologia em Análise e Desenvolvimento de Sistemas; Ciência da Computação; Engenharia de Computação e Tecnologia em Redes de Computadores.

${ }_{18}^{18}$ Cursos de Bacharelado e Licenciatura em Ciências Biológicas.

19 Cursos de Engenharia Civil; Tecnologia em Construção de Edifícios; Tecnologia em Saneamento Ambiental; Tecnologia em Eletrotécnica Industrial; Engenharia Elétrica; Engenharia de Produção e Engenharia Ambiental.
} 
Nota-se que a Grande Área do Conhecimento de Ciências Exatas e da Terra apresentou a média mais elevada de evasão, em 63,3\%. Em seguida, em ordem decrescente, vieram as áreas de Linguística, Letras e Artes (51,6\%); Ciências Humanas (49,9\%); Engenharias (49,3\%); Ciências Biológicas (45,3\%); Ciências Sociais Aplicadas (42,3\%); Ciências Agrárias (32,8\%) e Ciências da Saúde (33,8\%). Considerando-se a distribuição do período tomado para a análise (2008-2012), denota-se acentuada evasão entre 2011 e 2012. Nas áreas de Ciências da Saúde, Ciências Agrárias, Ciências Sociais Aplicadas e Linguística, Letras e Artes, evidencia-se redução da evasão de 2008 a 2009, com crescimento nos anos de 2010, 2011 e 2012. Por fim, nota-se que as áreas de Ciências Exatas e da Terra, Ciências Biológicas, Engenharias e Ciências Humanas apresentaram evasão crescente em todos os anos considerados.

Gráfico 2. Taxa média de evasão pelas Grandes Áreas do Conhecimento - 2008 a 2012

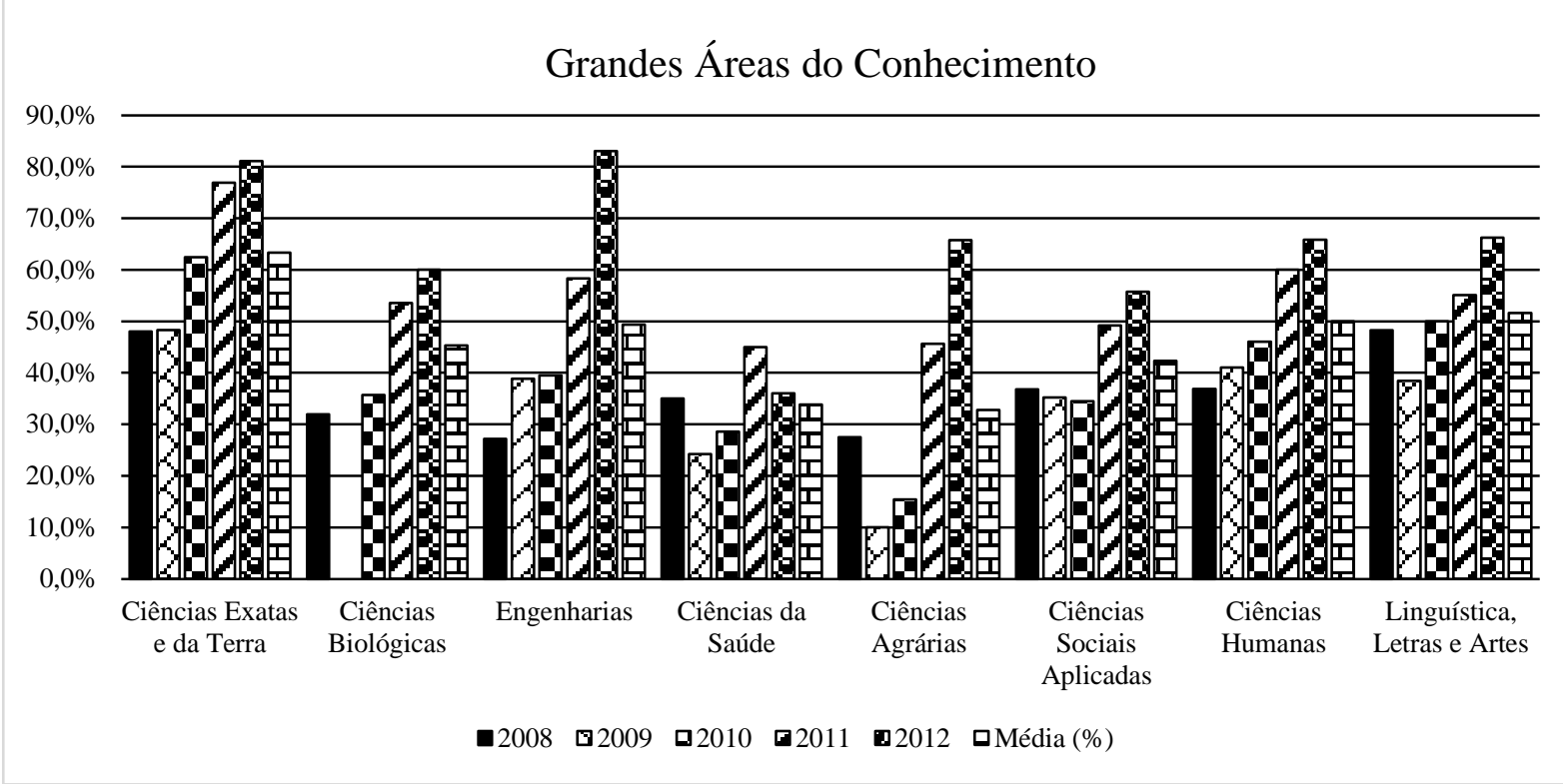

Fonte: Elaborado a partir dos microdados do Censo da Educação Superior (2009-2018).

Na pesquisa realizada por Davok e Bernard (2016) acerca da evasão em cursos de graduação da Universidade Federal de Santa Catarina (UFSC), no período de 2008 a 2010, as autoras constataram que os cursos da área de Ciências Exatas e da Terra apresentaram um índice médio de evasão de 58,8\%. Em contrapartida, os cursos da área de Ciências da Saúde apresentaram a menor evasão média no período analisado, registrando um percentual de 19,6\% de evasão. Em segundo lugar, estava a área de Ciências Agrárias, com um índice médio de evasão de 31,5\%. Outros autores, por exemplo, Adachi $(2009 ; 2017)$, estudando tal processo na Universidade Federal de Minas Gerais (UFMG) e na Universidade de São Paulo (USP), bem como Barbosa et al. (2017) na Universidade Federal de Uberlândia (UFU) e Veloso e Almeida (2000) na Universidade Federal de Mato Grosso (UFMT) também verificaram que a evasão é mais significativa em cursos da área

\footnotetext{
${ }^{20}$ Cursos de Odontologia; Fisioterapia; Farmácia e Nutrição.

${ }^{21}$ Cursos de Medicina Veterinária e Tecnologia em Alimentos.

${ }^{22}$ Cursos de Administração (Integral e Noturno); Tecnologia em Processos Gerenciais; Ciências Econômicas; Arquitetura e Urbanismo e Comunicação Social

${ }^{23}$ Filosofia; História; Bacharelado em Geografia; Psicologia e Pedagogia.

${ }^{24}$ Letras (Português/Espanhol e Português/Inglês).
} 
de Ciências Exatas e da Terra. Desta forma, tais estudos demonstram que a evasão nessa Grande Área do Conhecimento não parece ser uma problemática verificada apenas na UFMS, mas também se apresenta em outras instituições.

No gráfico 3 é salientada a média de evasão pelo grau acadêmico conferido ao aluno, qual seja: Bacharelado ${ }^{25}$ : Licenciatura $^{26}$ e Tecnológico ${ }^{27}$.

Dessa forma, evidencia-se que a média de evasão foi mais acentuada em cursos de grau acadêmico de Tecnologia ${ }^{28}$, correspondendo a $74,8 \%$; seguido pelos cursos de Licenciatura, com 53,7\%, e, com menor taxa, os cursos de Bacharelado, com 40,7\%. Notase, ainda, que os cursos de tecnologia apresentaram evasão crescente de 2010 a 2012. Já no caso dos cursos de licenciatura, verifica-se que nos anos de 2008 e 2009 a média de evasão se manteve inerte, em 43,7\%, no entanto; entre os anos de 2010 a 2012 houve elevação no crescimento. Em relação aos cursos de bacharelado, constatou-se decréscimo entre os anos de 2008 a 2010, entretanto, nos anos seguintes essa situação se inverte, e a evasão aumenta.

Conforme destacamos, a evasão é maior em cursos superiores de tecnologia na UFMS. Considerando essa informação, algumas características das carreiras de tecnologia são relatadas por Souza e Peixoto (2013). Assim, para as autoras, os principais atributos desses cursos são: foco, rapidez, inserção no mercado de trabalho e metodologia. O foco é a formação em um campo de trabalho definido, alinhado às necessidades do mercado de trabalho. A rapidez refere-se à oferta do curso com uma carga horária menor do que a habitual para sua oferta e funcionamento, visando a rápida inserção do aluno no mercado de trabalho, considerando-se as tendências do setor produtivo. Assim, a metodologia abrange técnicas, métodos e estratégias focadas na aprendizagem. As propostas didáticopedagógicas são voltadas para a prática.

Gráfico 3. Taxa média de evasão por grau acadêmico conferido - 2008 a 2012

\footnotetext{
${ }^{25}$ Cursos de Ciências Biológicas; Farmácia; Fisioterapia; Nutrição; Arquitetura e Urbanismo; Engenharia Ambiental; Engenharia Civil; Engenharia de Produção; Engenharia Elétrica; Geografia; Administração Noturno; Administração - Integral; Ciências Econômicas; Comunicação Social; Psicologia; Odontologia; Medicina Veterinária; Análise de Sistemas; Ciência da Computação e Engenharia de Computação.

${ }^{26}$ Cursos de Ciências Biológicas; Física; História; Filosofia; Letras - Português/Espanhol; Letras Português/Inglês e Pedagogia.

${ }^{27}$ Cursos de Tecnologia em Alimentos; Tecnologia em Construção de Edifícios; Tecnologia em Saneamento Ambiental; Tecnologia em Eletrotécnica Industrial; Tecnologia em Processos Gerenciais; Tecnologia em Análise e Desenvolvimento de Sistemas e Tecnologia em Redes de Computadores.

${ }^{28}$ No caso dos cursos tecnológicos, eles foram implantados na UFMS no ano de 2010, no contexto de ampliação do número de vagas e cursos, proporcionado, como já ressaltamos, pela participação da instituição junto ao Reuni.
} 


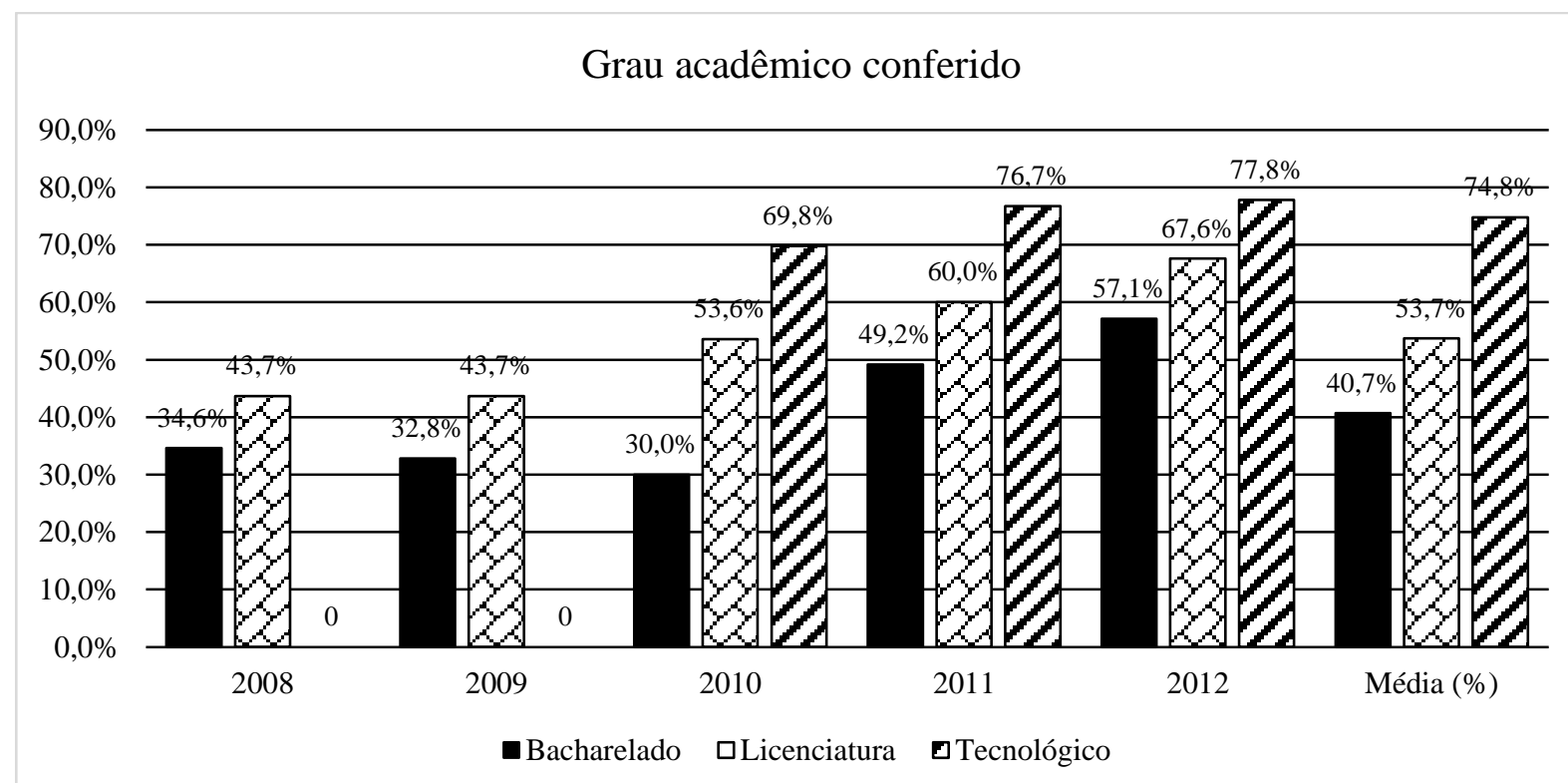

Fonte: Elaborado a partir dos microdados do Censo da Educação Superior (2009-2018).

No gráfico 4 é identificada a média de evasão por período de funcionamento do curso, isto é, integral ${ }^{29}$ e noturno ${ }^{30}$.

Desse modo, com relação aos dados do gráfico 4 , constatamos que a média de evasão foi mais alta em cursos que são ofertados no período noturno, representando $60,5 \%$. No que toca aos cursos ofertados no período integral, a média foi de $41,5 \%$. Além disso, considerando-se a disposição dos anos no gráfico, percebe-se que a evasão no período no noturno declinou de 2008 a 2009, com crescimento elevado nos anos seguintes, em especial, no ano de 2012 (75,1\%). Em relação aos cursos ofertados no período integral, observa-se redução da evasão entre os anos de 2008 a 2010, com aumento verificado nos anos de 2011 e 2012.

Os resultados encontrados por Adachi (2009; 2017), estudando o processo de evasão em duas grandes universidades da região Sudeste do Brasil, UFMG e USP, corroboram, em certa medida, com o resultado encontrado na UFMS, de predominância da evasão no período noturno. Para a autora, a evasão tende a ser mais alta para os cursos noturnos do que para as carreiras oferecidas no período diurno. Uma das razões apresentadas para evasão nesse período reside no fato das instituições não levarem em consideração a condição do estudante-trabalhador. Sabe-se que os cursos no período noturno demandam atividades em outros períodos, como: estágios, viagens de campo e demais atividades extracurriculares para a complementação da carga horária exigida para formação (ADACHI, 2017).

\footnotetext{
${ }^{29}$ Cursos de Ciências Biológicas - Bacharelado; Farmácia; Fisioterapia; Nutrição; Arquitetura e Urbanismo; Engenharia Ambiental; Engenharia Civil; Engenharia de Produção; Engenharia Elétrica; Administração Integral; Ciências Econômicas; Comunicação Social; Psicologia; Odontologia; Medicina Veterinária; Ciência da Computação; Engenharia de Computação; Licenciatura em Física; Letras - Português/Espanhol; Letras Português/Inglês; Pedagogia.

${ }^{30}$ Cursos de Administração - Noturno; Ciências Biológicas - Licenciatura; Licenciatura em História; Licenciatura em Filosofia; Geografia; Análise de Sistemas; Tecnologia em Alimentos; Tecnologia em Construção de Edifícios; Tecnologia em Saneamento Ambiental; Tecnologia em Eletrotécnica Industrial; Tecnologia em Processos Gerenciais; Tecnologia em Análise e Desenvolvimento de Sistemas e Tecnologia em Redes de Computadores.
} 
Gráfico 4. Taxa média de evasão por período de funcionamento do curso - 2008 a 2012

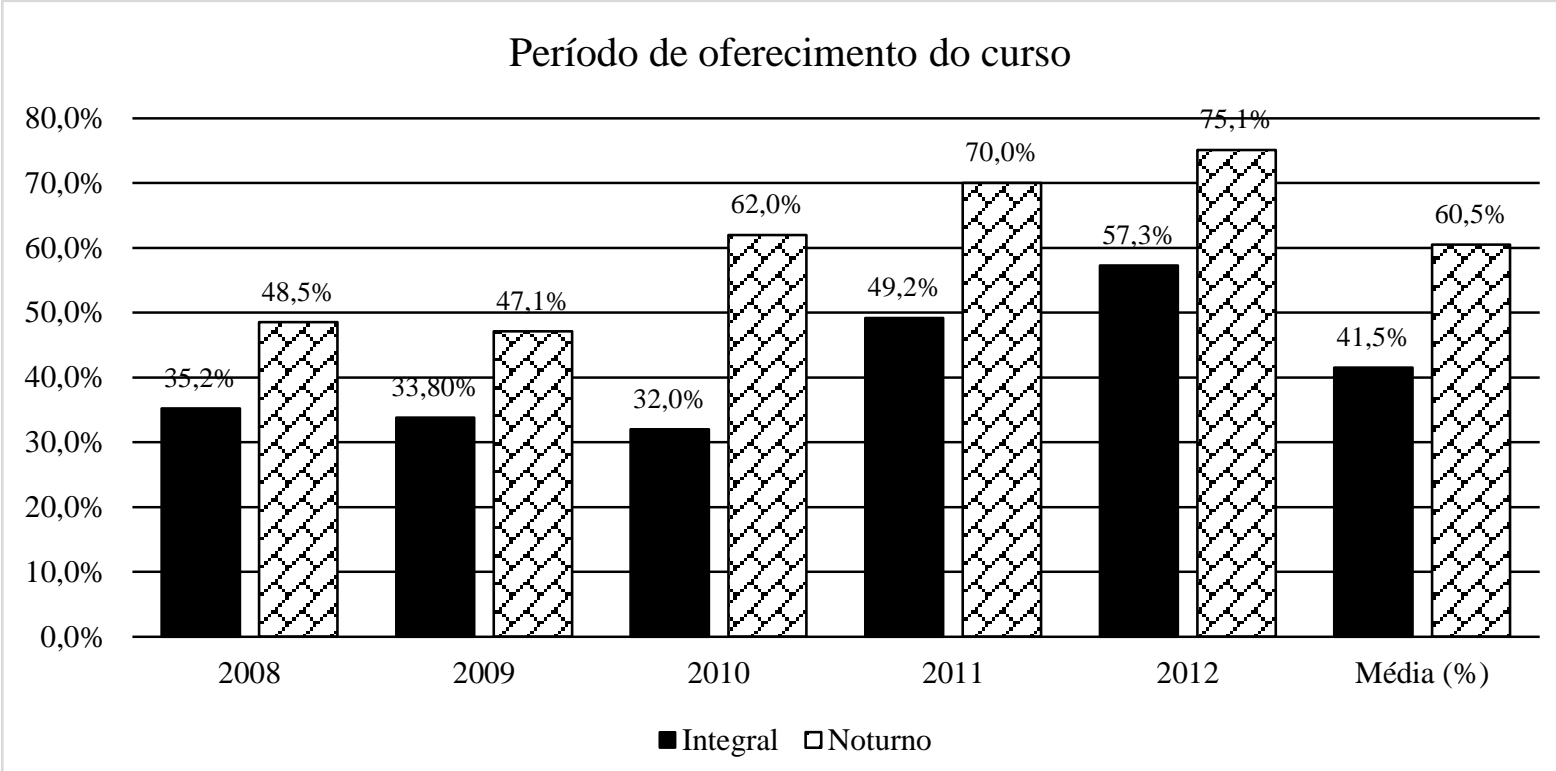

Fonte: Elaborado a partir dos microdados do Censo da Educação Superior (2009-2018).

Cabe lembrar que uma das diretrizes formuladas pelo Reuni era: Redução das taxas de evasão, ocupação de vagas ociosas e aumento de vagas de ingresso, especialmente no período noturno. Visando atingir tal meta, a UFMS buscou, em conformidade com o programa Reuni, a ampliação das vagas de ingresso neste período. Como exemplo, cita-se que do total de vagas ofertadas no ano de $2011,48,79 \%$ foram disponibilizadas no período noturno; $46,58 \%$ no período integral; e $1,26 \%$ e $3,37 \%$ nos períodos matutino e vespertino (UFMS, 2012).

Em que pesem as ações do governo federal em ampliar o oferecimento de vagas e cursos no período noturno, visando a redução da taxa de evasão e ocupação de vagas ociosas, no caso da UFMS, a princípio, tais medidas não parecem ter surtido o efeito esperado. Por exemplo, verificamos o crescimento significativo do número de estudantes evadidos, que parece ter seguido a mesma tendência de crescimento do número de vagas; outro fato é que os cursos criados nesse período, particularmente os cursos tecnológicos, apresentam uma evasão significativa, ultrapassando $70 \%$; e, por fim, a evasão tendeu a ser mais expressiva em cursos noturnos do que em carreiras ofertadas no período integral.

\section{CONSIDERAÇÕES FINAIS}

Este artigo apresentou resultados preliminares sobre o processo de evasão na UFMS no período em que foi implementado o programa Reuni, considerando estudantes ingressantes via vestibular e por meio do Sisu nos anos de 2008 a 2012, no campus de Campo Grande.

Em suma, evidenciou-se no período analisado, que a evasão foi elevada, em 43,5\%. $\mathrm{E}$, mais precisamente, o ano de 2011 denotou a taxa mais significativa de evasão (56,3\%). Dessa forma, pode-se afirmar que o período de crescimento da evasão na UFMS coincidiu com a mudança do processo de seleção de estudantes, por meio da adoção do Sisu, o que vai ao encontro de discussões já presentes na literatura produzida sobre a temática. Cabe destacar que o estudo de tal relação, contudo, ainda permanece como desafio para futuras investigações. Além disso, constatou-se que cursos da Grande Área do Conhecimento 
Ciências Exatas e da Terra apresentaram médias mais expressivas de evasão $(63,3 \%)$, assim como os cursos de grau acadêmico em tecnologia $(74,8 \%)$ e as carreiras ofertadas no período noturno $(60,5 \%)$.

Frente a isso, quais os artifícios utilizados pela UFMS para contenção do processo de evasão? Sabe-se que o objetivo central do programa Reuni era criar condições para a ampliação do acesso e permanência na educação superior, no nível de graduação. Desse modo, para garantir o acesso e a permanência de estudantes, a UFMS vem lançando mão de um conjunto de medidas. Conforme a análise exploratória dos Planos de Desenvolvimento Institucional (PDI) - 2010-2014 e 2015-2019, a universidade vem aumentando a expansão do número de programas e auxílios de permanência; de bolsas monitoria; o oferecimento de disciplinas em períodos especiais; a ocupação de vagas ociosas, mediante processos de ingresso por meio de transferências externas, como portadores de diploma; transferências internas e flexibilização no processo de reingresso. Mais recentemente, em 2017, a universidade criou duas novas formas de ingresso, retomando o vestibular próprio e adotando o Processo de Avaliação Seriada Seletiva (PASSE). Tais iniciativas demonstram a preocupação da referida Ifes com relação ao processo de evasão que tem se intensificado nos últimos anos.

Dessa forma, se a ampliação do acesso é basilar para que se possa almejar a universalização da educação superior, tal medida precisa ser garantida por meio de ações de permanência, para que os dados de evasão sejam minimizados e para que a educação pública seja um direito de todos. Em função disso, torna-se necessário a intensificação dos esforços conjunto de pesquisadores e gestores, na direção de produzir conhecimento científico que permita identificar as possíveis medidas que viabilizem acesso e permanência ampliados na educação superior pública.

\section{REFERÊNCIAS}

ADACHI, A. A. C. T. Evasão e evadidos nos cursos de graduação da Universidade Federal de Minas Gerais. 2009. 214f. Dissertação (Mestrado em Educação) -Faculdade de Educação, Universidade Federal de Minas Gerais. Belo Horizonte: 2009.

ADACHI, A. A. C. T. Evasão de estudantes de cursos de graduação da USP: ingressantes nos anos de 2002, 2003 e 2004. 2017. 294f. Tese (Doutorado em Educação) - Faculdade de Educação, Universidade de São Paulo. São Paulo: 2017.

BARBOSA, J. P. G. et al. A adoção do SISU e a evasão na Universidade Federal de Uberlândia. Revista Ibero-Americana de Estudos em Educação, v. 12, n. 2, p. 722-738, 2017.

BRASIL. Ministério da Educação. Secretaria de Educação Superior. Comissão Especial de Estudos sobre a Evasão nas Universidades Públicas Brasileiras. Diplomação, retenção e evasão nos cursos de graduação em instituições de Ensino Superior públicas. Brasília: ANDIFES/ABRUEM/ SESu/MEC, 1997.

BRASIL. Decreto $n^{\circ}$ 6.096, de 24 de abril de 2007. Institui o Programa de Apoio a Planos de Reestruturação e Expansão das Universidades Federais - REUNI. Brasília: 2007. Disponível em: http://www.planalto.gov.br/ccivil_03/_Ato20072010/2007/Decreto/D6096.htm. Acesso em: 21 out. 2019. 
BRASIL. Portaria normativa $n^{\circ} 21$, de 5 de novembro de 2012. Dispõe sobre o Sistema de Seleção Unificada - Sisu. Brasília: 2012. Disponível em: http://r1.ufrrj.br/sisu/wpcontent/uploads/2015/12/portaria-normativa-mec-n21-de-05-11-2012.pdf. Acesso em: 05 jul. 2017.

DAVOK, D. F.; BERNARD, R. P. Avaliação dos índices de evasão nos cursos de graduação da Universidade do Estado de Santa Catarina - UDESC. Avaliação: Revista da Avaliação da Educação Superior, Campinas; Sorocaba, v. 21, n. 2, p. 503-521, jul. 2016.

\section{INSTITUTO NACIONAL DE ESTUDOS E PESQUISAS EDUCACIONAIS ANÍSIO} TEIXEIRA. Microdados do Censo da Educação Superior (2009-2018). Brasília: Inep, 2019. Disponível em: http://portal.inep.gov.br/microdados. Acesso em: 28 set. 2019.

LI, D. L. O novo Enem e a plataforma Sisu: efeitos sobre a migração e a evasão estudantil. 2016. 108f. Dissertação (Mestrado em Economia) - Faculdade de Economia, Administração e Contabilidade, Universidade de São Paulo. São Paulo: 2016.

LUZ, J. N. N. da; VELOSO, T. C. M. A. O Sistema de Seleção Unificada (SiSU): refletindo sobre o processo de seleção. Revista Educação e Fronteiras On-Line, DouradosMS, v. 4, n. 10, p. 68-83, jan./abr. 2014.

SOUZA, J. B. de; PEIXOTO, M. do C. de L. Política de expansão dos cursos superiores de tecnologia: nova face da educação profissional e tecnológica. In: JEZINE, E; BITTAR, M. Políticas de Educação Superior no Brasil: expansão, acesso e igualdade social. UFPB:

João Pessoa, 2013. p. 86-102

UNIVERSIDADE FEDERAL DE MATO GROSSO DO SUL (UFMS). Relatório de Gestão 2009. Campo Grande: 2010

UNIVERSIDADE FEDERAL DE MATO GROSSO DO SUL (UFMS). Relatório de Gestão 2011. Campo Grande: 2012.

UNIVERSIDADE FEDERAL DE MATO GROSSO DO SUL (UFMS). Plano de Desenvolvimento Institucional 2010-2014. Campo Grande: 2012-2015.

UNIVERSIDADE FEDERAL DE MATO GROSSO DO SUL (UFMS). Anuário Informações Estatísticas 2009-2011. Universidade Federal de Mato Grosso do Sul. Campo Grande: [2015?].

UNIVERSIDADE FEDERAL DE MATO GROSSO DO SUL (UFMS). Resolução $n^{\circ}$ 106, de 04 de março de 2016. Orientações Gerais para a Elaboração de Projeto Pedagógico de Curso de Graduação da Fundação Universidade Federal de Mato Grosso do Sul. Campo Grande: $2016 b$.

UNIVERSIDADE FEDERAL DE MATO GROSSO DO SUL (UFMS). Plano de Desenvolvimento Institucional 2015-2019: realinhado. Campo Grande: 2017. 
VELOSO, T. C. M. A.; ALMEIDA, E. P. de. Evasão nos cursos de graduação da Universidade Federal de Mato Grosso, campus universitário de Cuiabá - um processo de exclusão. Série-Estudos, Campo Grande, n. 13, p. 133-148, jan./jun. 2002.

Recebido em: 23/01/2020

Aprovado: 26/03/2020 